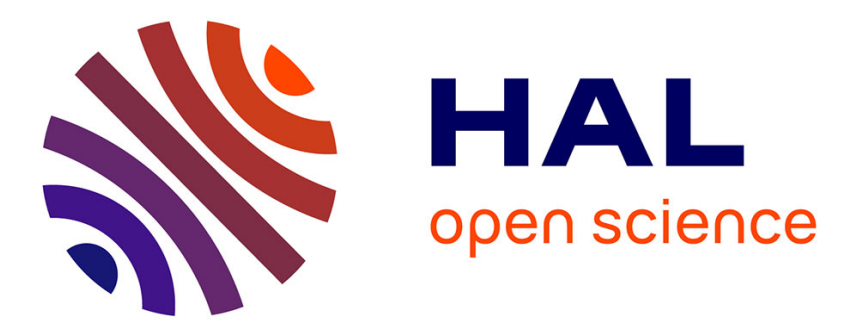

\title{
Spontaneous Buckling Induced by the Adsorption of Charged Copolymers at the Air-Water Interface
}

Philippe Fontaine, Jean Daillant, Patrick Guenoun, Michel Alba, Alan

Braslau, Jimmy Mays, Jean-Marc Petit, François Rieutord

\section{To cite this version:}

Philippe Fontaine, Jean Daillant, Patrick Guenoun, Michel Alba, Alan Braslau, et al.. Spontaneous Buckling Induced by the Adsorption of Charged Copolymers at the Air-Water Interface. Journal de Physique II, 1997, 7 (3), pp.401-407. 10.1051/jp2:1997133 . jpa-00248451

\section{HAL Id: jpa-00248451 https://hal.science/jpa-00248451}

Submitted on 1 Jan 1997

HAL is a multi-disciplinary open access archive for the deposit and dissemination of scientific research documents, whether they are published or not. The documents may come from teaching and research institutions in France or abroad, or from public or private research centers.
L'archive ouverte pluridisciplinaire $\mathbf{H A L}$, est destinée au dépôt et à la diffusion de documents scientifiques de niveau recherche, publiés ou non, émanant des établissements d'enseignement et de recherche français ou étrangers, des laboratoires publics ou privés. 


\title{
Spontaneous Buckling Induced by the Adsorption of Charged Copolymers at the Air-Water Interface
}

\author{
Philippe Fontaine $\left({ }^{1}\right)$, Jean Daillant $\left({ }^{1, *}\right)$, Patrick Guenoun $\left({ }^{1}\right)$, Michel Alba $\left({ }^{1}\right)$, \\ Alan Braslau $\left({ }^{1}\right)$, Jimmy W. Mays $\left({ }^{2}\right)$, Jean-Marc Petit $\left({ }^{3}\right)$ \\ and François Rieutord $\left({ }^{3}\right)$ \\ ( ${ }^{1}$ Service de Physique de l'État Condensé, CEA Saclay, 91191 Gif-sur-Yvette Cedex, France \\ $\left({ }^{2}\right)$ Department of Chemistry, University of Alabama, Birmingham, AL 35294, USA \\ $\left({ }^{3}\right)$ Service des Interfaces et Matériaux Moléculaires et Macromoléculaires, CEA Grenoble, \\ 17 rue des Martyrs, 38054 Grenoble Cedex, France
}

(Received 29 November 1996, revised 19 December 1996, accepted 10 January 1997)

PACS.68.10.-m - Fluid surfaces and fluid-fluid interfaces

PACS.61.10.-i - X-ray diffraction and scattering

PACS.61.25.-f - Studies of specific liquid structures

\begin{abstract}
We present results of the adsorption of charged diblock copolymers at the free interface between air and solution. These copolymers are water soluble and act as surfactants above some concentration. Through thermodynamic and diffuse X-ray surface scattering measurements, we demonstrate the influence of the concentration on the formed adsorbed layer. While sufficiently long copolymers adsorb by forming structures which do not deform the interface, short copolymers are shown to induce buckling of the interface due to interchain interactions.
\end{abstract}

\section{Introduction}

The influence of host molecules on the properties of interfaces or membranes has recently received a great deal of attention, and in particular the controlled modification of their elastic and mechanical properties is of major importance. For instance, the anchoring of copolymers onto liposomes can mimic interesting biological situations such as the mechanical action of the cytoskeleton $[1,2]$. Adsorption or anchoring of a polymer in a lamellar phase has also been predicted $[3,4]$ to change the elastic constants of the lamellar phase and possibly induce defects or strain. Even for interfaces where only one component is adsorbed, the equilibrium of stresses can lead to interesting situations where the surface tension is not the dominant force anymore. In particular, intriguing cases of buckling of a polymerized or solid Langmuir film have been reported $[5,6]$. The potential importance of spontaneous curvature in such situations has been stressed recently [7]. The spontaneous curvature and the elastic constants of copolymer monolayers adsorbed at an interface have been already calculated in several situations $[8,9]$. These calculations have generally dealt with neutral copolymers at the interface of selective solvents of both blocks. Diblock copolymers can indeed self-assemble in different ways such as

$\left(^{*}\right)$ Author for correspondence (e-mail: daillant@amoco.saclay.fr) 
micelles or lamellar phases in presence of a selective solvent for one of the blocks or adsorbed layers in presence of a selective surface [10]. The latter configuration is of prime importance for many applications of industrial relevance [11] since copolymers can play the role of macrosurfactant in situations of interface tailoring such as colloidal protection. The use of charged copolymers is of increasing importance since they have been recognized to be good candidates for protection in water or polar media due to the high stretching of the chains and the weak sensitivity to added salt [12]. Moreover, interfaces formed by these charged copolymers create situations where the test of particular behaviors of polyelectrolytes can be done, a situation which is still of great interest [13].

The system whose study is reported here is the free surface of solutions of charged diblock copolymers. The adsorbed layer is constrained to be in thermodynamic equilibrium with the bulk solution. The building of the monolayer is due to the amphiphilic nature of the charged diblock copolymer and is well-corroborated by the lowering of surface tension. However, interactions between adsorbed chains at the interface cannot be neglected, even for relatively small adsorbed amounts of polymer, because of the electrostatic repulsion between chains. In some cases, depending primarily on the architecture of the polymer, the experimental study presented here suggests that the most energetically favorable configuration is a spatial modulation of the interface, like in buckling phenomena. In the first part, we describe the materials used and recall what is known about their thermodynamic behavior. In the second part, we define our experimental strategy, including the experimental details about the X-ray diffuse surface scattering. Then, in the third part we present the results and the conclusions which can be drawn from them. In the last part, we derive an interpretation which accounts for the experimental results and conclude by depicting the future work which is envisioned.

\section{Chemistry and Thermodynamics of the System}

We made use of two diblock copolymers (labeled as $(128,4)$ and $(211,13)$ from their number of segments, see below) made of one short hydrophobic moietie (polytertiarybutylstyrene, PtBS) and of one longer polyelectrolytic part (polystyrenesulfonate, PSSNa) ionized at 90\%. These polymers where synthesized by anionic polymerization and appropriate post-polymerization chemistry [14] and their characteristics are as follows in terms of number of segments: $N(\mathrm{PSSNa})=128, N(\mathrm{PtBS})=4$ for the one denoted $(128,4) ; N(\mathrm{PSSNa})=211, N(\mathrm{PtBS})=13$ for the one denoted $(211,13)$. Polydispersities are well under 1.1 for both polymers. These copolymers are water soluble and are able to micellize in solution for the $(211,13)$, or apparently do not form micelles $(128,4)$. The micelle formation for such symmetric diblocks results of a balance between the energy gained by the hydrophobic segments upon aggregation and the loss of energy which can result from tethering charged chains together and forming a stretched corona. Such a stretched corona is due to the osmotic pressure of the counter-ions trapped within the micelle [15]. The low number of hydrophobic segments of the $(128,4)$ polymer could explain why, contrary to the $(211,13)$, no apparent micellization can be observed. However, for both copolymers, a substantial reduction of surface tension can be observed at sufficiently high concentration. This shows that, despite its low number of hydrophobic segments, even $(128,4)$ can form an adsorbed structure at the air-solution interface. Surface tension measurements of both copolymer solutions have been carried out as a function of concentration and as a function of time for copolymer solutions with no added salt. A Wilhelmy balance using a filter paper as a sensor was used. This method was already qualified for such copolymers [16] by checking that no adsorption can be detected on the sensor. All measurements, like X-ray measurements (see below) were carried out at ambient temperature. Results are shown in Figure 1 where, for all measured concentrations, an equilibrium is reached about after 10 hours. 


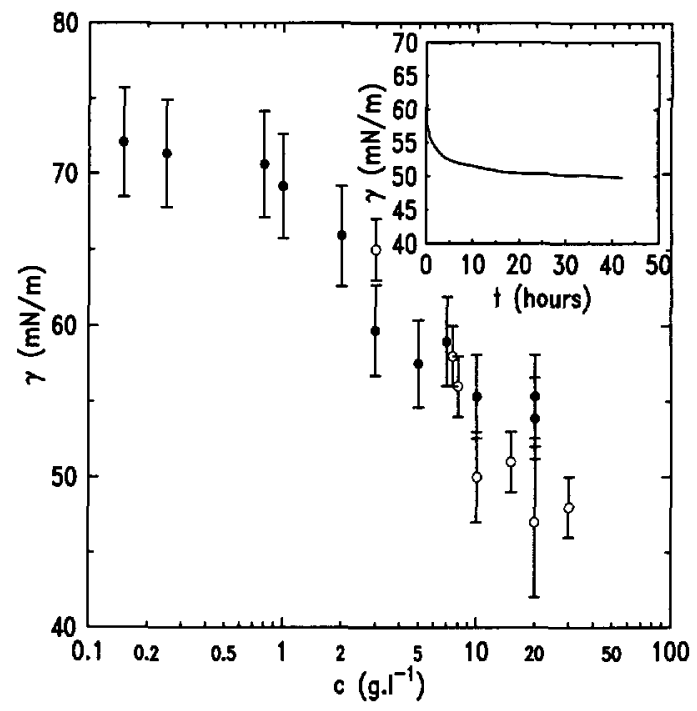

Fig. 1. - Surface tension vs. concentration for the $(128,4)$ polymer (empty circles) and the $(211,13)$ polymer (filled circles). Inset: surface tension of $(128,4)$ at $20 \mathrm{~g} / \mathrm{l}$ as a function of time.

The surface tension is always lowered with respect to pure water. Whereas the surface tension of $(128,4)$ appears lower than that of $(211,13)$ at high solution concentration, the relative importance of the error bars and the lack of determination of the surface concentration precludes any definite conclusion. Note that homopolyelectrolytes such as PSSNa always induce an increase of the surface tension in absence of added salt. The ability to achieve an equilibrium is already worth discussing with respect to some theoretical considerations which take into account the image charge induced by a charged chain as it adsorbs at the air-water interface $[17,18]$. We postpone a detailed discussion about this kinetics for another publication.

Several solutions of copolymer were prepared prior to the runs by dissolving the polymer in ultrapure deionized water (Millipore of resistivity larger than $18 \mathrm{M} \Omega \mathrm{cm}$ ). We studied several solutions of $(128,4)$ at respectively $3,10,20$ and $30 \mathrm{~g} / 1$ and one solution of $(211,13)$ at $8 \mathrm{~g} / 1$. Dedicated troughs made of teflon were used for each solution both for ageing and for the scattering experiments.

\section{Experiment}

We made use of X-ray reflectivity and surface scattering in order to quantitatively determine the adsorbed structures. The reflectivity measurements were carried out on a reflectometer equipped with a fine focus copper tube $(\lambda=0.154 \mathrm{~nm})$ followed by a $\operatorname{Si}(111)$ monochromator and $110 \mu \mathrm{m}$ divergence slits. The reflected intensity was measured using $200 \mu \mathrm{m}$ analysis slits and a NaI scintillator. "Rocking curves" were performed around each normal $q_{z}$ wave-vector transfer value in order to substract the background. As the contrast between the adsorbed layer and water is very low, the curves could be analyzed using only a single index step between air and water in a first approximation. The surface fluctuations were analyzed using the standard scattering cross section for thermally excited capillary waves [5]. Reflectivity results are shown in Figure 2. 


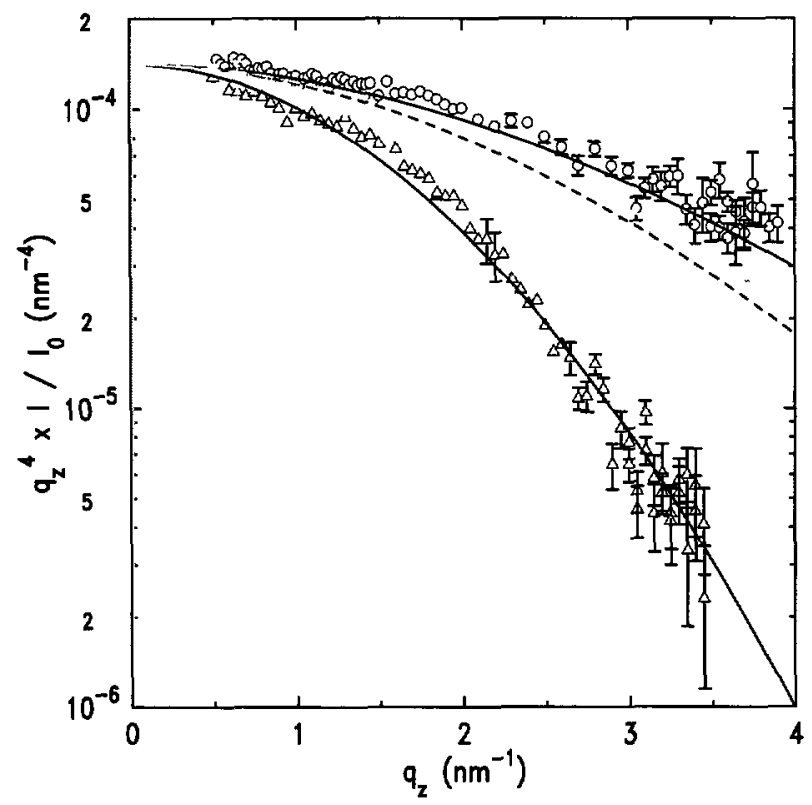

Fig. 2. - Reflectivity curves for $(211,13)$ at $8 \mathrm{~g} / \mathrm{l}$ (circles), $(128,4)$ at $3 \mathrm{~g} / \mathrm{l}$ (grey squares), and $(128,4)$ at $30 \mathrm{~g} / 1$ (triangles). Solid lines are fits to the data as indicated in the text with additionnal roughness factors equal to $0.2 \mathrm{~nm}$ for $(128,4)$ at $3 \mathrm{~g} / \mathrm{l}$ and $0.42 \mathrm{~nm}$ at $30 \mathrm{~g} / \mathrm{l}$. The dashed lines are the corresponding calculations without the additionnal roughness factors.

Clearly the $(211,13)$ solution $(8 \mathrm{~g} / \mathrm{l})$ is nicely fitted by this model without any additional roughness. On the contrary, solutions of the $(128,4)$ polymer all necessitate the inclusion of an additional roughness which increases with concentration. Since reflectivity measurements give information about the structure normal to the interface only, diffuse surface scattering experiments at grazing angles have been performed in order to elucidate the origin of this roughness.

Diffuse scattering experiments were performed at the ESRF, BM32 line (at $8.9 \mathrm{keV}, 0.139 \mathrm{~nm}$ ) since such experiments need a high flux and a high resolution. The experimental configuration has been detailed elsewhere [19] and only the main features are reported here. Two different resolutions were used in order to eliminate systematic errors.

In order to minimize the background, the troughs were maintained under a gentle helium flux, and the grazing angle of incidence $\theta_{\mathrm{i}}$ was fixed below the critical angle for total external reflection. The scattered intensity $I(\mathbf{q})$ was then recorded as a function of the detector angle above the surface in the plane of incidence $\theta_{\mathrm{d}}$, see Figure 3 . With this geometry $I(\mathbf{q})$ essentially writes as [20]:

$$
I(\mathbf{q}) \propto \int_{\operatorname{Res}} F\left(q_{z}\right) \cdot\langle z(\mathbf{q}) z(-\mathbf{q})\rangle
$$

where $F\left(q_{z}\right)$ gives account of the vertical interfacial structure, and $\langle z(\mathbf{q}) z(-\mathbf{q})\rangle$ is the inplane correlation function, and the resolution is mainly given by the slits in the beam-path. The results were again analyzed using a single index step and a standard correlation function 


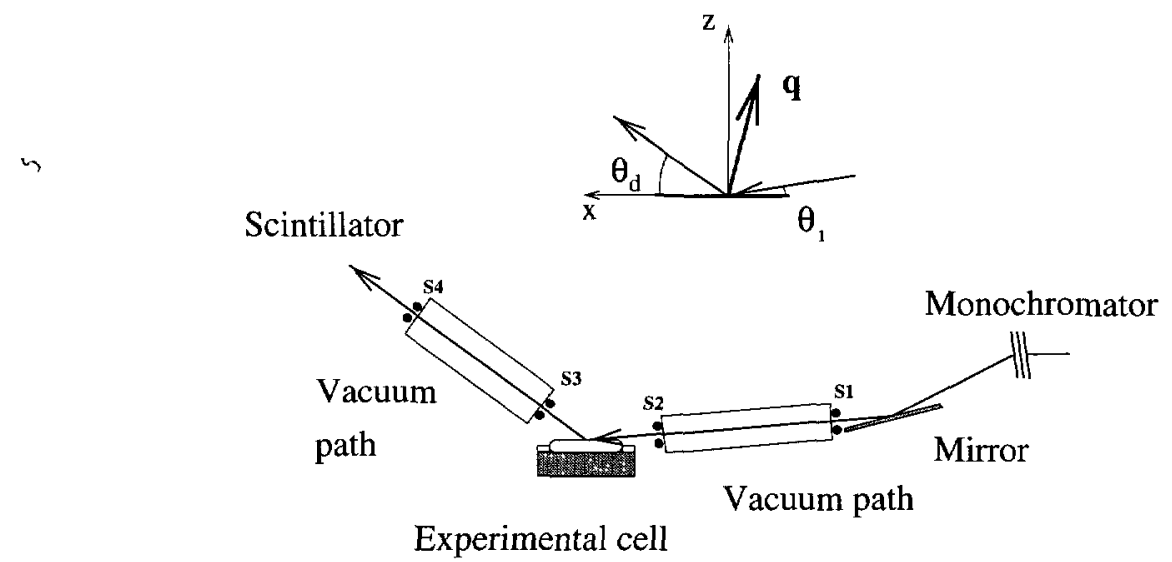

Fig. 3. - Experimental configuration. The sample to detector distance is $720 \mathrm{~mm}$ and the $s_{2}$ to $s_{3}$ distance is $510 \mathrm{~mm}$. The vertical $\times$ horizontal openings of the slits are respectively: resolution $A$ $s_{2} 0.1 \mathrm{~mm} \times 0.5 \mathrm{~mm}, s_{3} 2 \mathrm{~mm} \times 2 \mathrm{~mm}, s_{4} 0.5 \mathrm{~mm} \times 4 \mathrm{~mm}$; resolution B $s_{2} 0.1 \mathrm{~mm} \times 0.5 \mathrm{~mm}$, $s_{3} 0.5 \mathrm{~mm} \times 2 \mathrm{~mm}, s_{4} 0.2 \mathrm{~mm} \times 4 \mathrm{~mm}$. The inset shows the corresponding scattering geometry.

including the measured surface tension [19]:

$$
\langle z(0,0) z(x, y)\rangle=\frac{k_{\mathrm{B}} T}{2 \pi \gamma} \times\left[K_{0}\left(r \sqrt{\frac{\Delta \rho g}{\gamma}}\right)-K_{0}\left(r \sqrt{\frac{\gamma}{K}}\right)\right]
$$

where $K_{0}$ is the modified Bessel function of second kind of order $0, K$ is the bending rigidity which was assumed to be on the order of $k_{\mathrm{B}} T$ in all calculations [21], and $r=\sqrt{x^{2}+y^{2}}$. The measured scattered intensity is represented in Figure 4.

As compared to a pure capillary wave scattering given by equation (2), one can note an extra-scattering due to the polymer film of $(128,4)$ (large peak around $10^{7} \mathrm{~m}^{-1}$ ). This is not observed with the $(211,13)$ polymer. It should be noticed that, although our measurements actually involve a coupling between $q_{x}$ and $q_{z}$, reflectivity measurements ( $q_{z}$ only) prove that the extra-scattering is due to surface corrugations and not to a structural effect as included in $F\left(q_{z}\right)$ : the only source of contrast is provided by the air-solution interface. These corrugations for the $(128,4)$ were taken into account by adding a contribution to the correlation function:

$$
\langle z(0,0) z(x, y)\rangle=h_{0}^{2} J_{0}\left(\frac{2 \pi r}{\Lambda}\right) \mathrm{e}^{-r^{2} / 2 \xi^{2}}
$$

where $J_{0}$ is the Bessel function of first kind of order 0 , and by multiplying the intensity by the additional roughness factor determined from the reflectivity experiments. This correlation function is the one obtained using a simple sine corrugation of amplitude $h_{0}$ with coherence length $\xi$ angularly averaged in the plane of the surface. As the correlation length $\xi(50 \mathrm{~nm})$ is on the order of the wave-length $\Lambda(200 \mathrm{~nm})$, the in-plane order is quite disordered exhibiting only a characteristic size. We interpret the occurrence of this corrugation as due to the development of an instability of wave-vector $Q=2 \pi / \Lambda$ in the plane. The wavelength of modulation $\Lambda$ is insensitive to concentration, and only the amplitude $h_{0}$ increases upon concentration of polymer from $0.1 \pm 0.02 \mathrm{~nm}$ at $3 \mathrm{~g} / 1$ to $0.20 \pm 0.04 \mathrm{~nm}$ at $20 \mathrm{~g} / \mathrm{l}$.

The deformation of the interface is probably favored by the repulsive interactions between adsorbed chains, since curvature favors a larger space between chains at the same area per chain. 


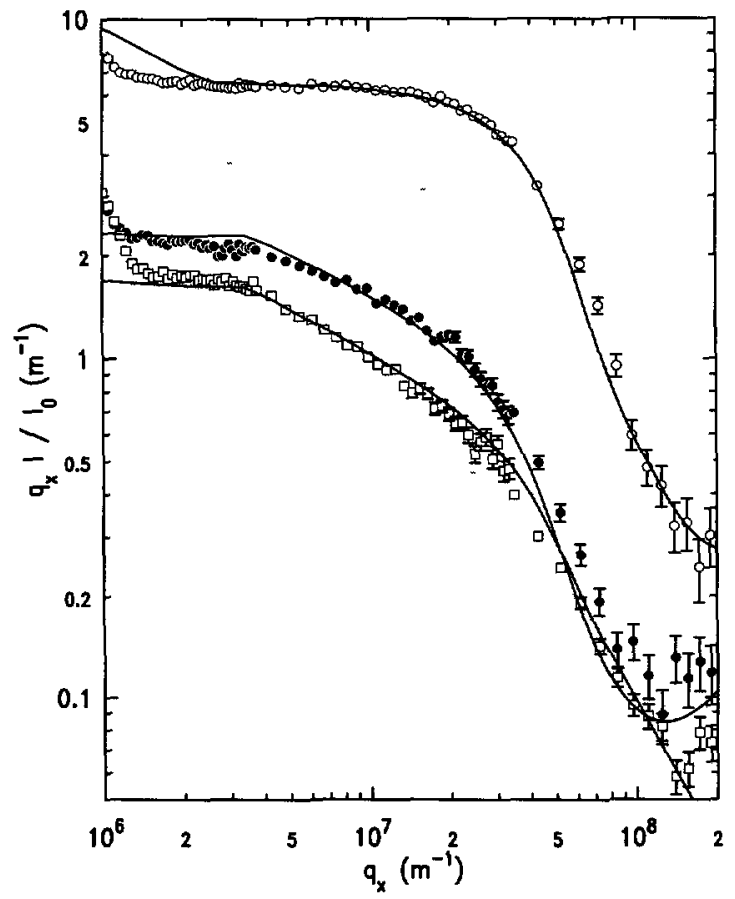

Fig. 4. - Scattering intensity $\times q_{x}$ as a function of $q_{x}$. Solid lines are fits to the data as described in text. Resolution A: water (grey triangles) and $(128,4)$ polymer at $20 \mathrm{~g} / 1$ (circles). The dashed line is a calculation with the correlation function equation (2) only and a surface tension $\gamma=48 \mathrm{mN} / \mathrm{m}$ as measured for the $(128,4)$ polymer. Resolution B: water (inverted grey triangles), $(128,4)$ polymer at $3 \mathrm{~g} / \mathrm{l}$ (squares) and $20 \mathrm{~g} / \mathrm{l}$ (filled circles). Dashed line for the $20 \mathrm{~g} / \mathrm{l}$ solution as indicated above.

However, curvature costs capillary energy and defect energy localized at the walls between curved zones of extension $\Lambda$. The equilibrium value of $\Lambda$ should come out of a minimization of the full grand potential including the above listed surface energies and the bulk chemical potential. Its precise calculation is clearly out of the scope of our study although a correct estimation of the spontaneous curvature of the adsorbed layer should be a first step in the calculation of $Q$. An intriguing question is why this phenomenon does not occur with the longer and more symmetrical $(211,13)$. Although not shown in Figure 2 because of a lack of place, the experimental data for $(211,13)$ are actually well-described by a pure capillary wave model with an input given by the measured surface tension. We speculate that this could be related to the ability for $(211,13)$ to micellize since such a micellization can also occur at the surface [22] and would allow to accommodate curvature. Crucial experimental tests should be the study of such adsorbed layers when electrolyte is added in order to decide if electrostatic interactions between chains or osmotic effects of confined counterions are essential.

\section{Acknowledgments}

Support from NATO under grant number CRG930892 is gratefully acknowledged. We also wish to thank A. Pesnelle for assistance during the experiments. 


\section{References}

[1] Lasic D.D., Liposomes, from Physics to Applications (Elsevier, Amsterdam, 1995).

[2] Simon J., Kühner M., Ringsdorf H. and Sackmann E., Chem. Phys. Lipids 76 (1995) 241.

[3] Lipowski R., Europhys. Lett. 30 (1995) 197; Hiergeist C. and Lipowski R., J. Phys. II France 6 (1996) 1465.

[4] Hristova K. and Needham D., Macromolecules 28 (1995) 91.

[5] Bourdieu L., Daillant J., Chatenay D., Braslau A. and Colson D., Phys. Rev. Lett. 72 (1994) 1502.

[6] Saint-Jalmes A., Graner F., Assenheimer M. and Gallet F., Short and Long Chains at Interfaces, J. Daillant, P. Guenoun, C. Marques, P. Muller and J. Tran Thanh Van, Eds. (Editions Frontières, Gif-sur-Yvette, 1995) p. 229.

[7] Hu J.G. and Granek R., J. Phys. II France 6 (1996) 999.

[8] Cantor R.S., Macromolecules 14 (1981) 1186.

[9] Wang Z.G. and Safran S.A., J. Chem. Phys. 94 (1991) 679.

[10] Halperin A., Tirrell M. and Lodge T.P., Adv. Polym. Sci. 31 (1992) 100.

[11] Napper D., Polymeric Stabilization of Colloidal Dispersions (Academic Press, London, 1983).

[12] Pincus P., Macromolecules 24 (1991), 2912; Guenoun P., Schalchli A., Sentenac D., Mays J.W. and Benattar J.J., Phys. Rev. Lett. 74 (1995) 3628.

[13] Barrat J.L. and Joanny J.F., Adv. Chem. Phys. XCIV (1996) 1; Förster S. and Schmidt M., Adv. Polymer Sci. 120 (1995) 51.

[14] Valint P.L. and Bock J., Macromolecules 21 (1988) 175; Argillier J.-F., Mao G.-Z., Tirrell M., Mays J.W. and Chen Y.-J., submitted to Macromolecules (1996).

[15] Huang C., Olvera de la Cruz M., Delsanti M. and Guenoun P., submitted to Macromolecules.

[16] Guenoun P., Davis H.T., Mays J.W. and Tirrell M., Macromolecules 29 (1996) 3965.

[17] de Gennes P.G., Cours du Collège de France (1990), unpublished.

[18] Wittmer J. and Joanny J.F., Macromolecules 26 (1993) 2691.

[19] Daillant J., Quinn K., Gourier C. and Rieutord F., J. Chem. Soc. Faraday Trans. 92 (1996) 505.

[20] In fact we used the full Distorted Wave Born Approximation as described in reference [19] for analyzing the data.

[21] This is not obvious because much larger bending rigidities might be expected for polymer brushes, see e.g. [8] and [9]. However, this gives a nice fit to the longer $(211,13)$ polymer, and in any case the use of a larger bending rigidity in the model would only lead us to introduce a larger additional roughness.

[22] Li Z., Zhao W., Quinn J., Rafailovich M.H., Sokolov, J., Lennox R.B., Eisenberg A., Wu X.Z., Kim M.W., Sinha S.K, and Tolan M. Langmuir 11 (1995) 4785. 